\title{
KOREKSI INSTRUMEN PADA SEISMOMETER BROADBAND TRILIUM- 120P DAN SHORT-PERIOD DS-04A CO-LOCATED DI STASIUN GEOFISIKA DENPASAR (STUDI KASUS: GEMPABUMI LOMBOK 31 MARET 2016)
}

\author{
INSTRUMENT CORRECTION ON CO-LOCATED TRILIUM-120P BROADBAND \\ SEISMOMETER AND DS-04A SHORT-PERIOD SEISMOMETER AT DENPASAR \\ GEOPHYSICS STATION (CASE STUDY: LOMBOK EARTHQUAKE MARCH 31'H 2016)
}

\author{
I Putu Dedy Pratama1 ${ }^{*}$, Pande Komang Gede Arta Negara², Dwi Karyadi Priyanto ${ }^{1}$ \\ ${ }^{1}$ Stasiun Geofisika Denpasar \\ 2Stasiun Geofisika Mataram \\ *E-mail: checkmate_mail@yahoo.co.id
}

Naskah masuk: 01 Juli $2020 \quad$ Naskah diperbaiki: 09 Maret $2021 \quad$ Naskah diterima: 16 Maret 2021

\begin{abstract}
ABSTRAK
Dalam penjalarannya sinyal seismik yang terekam oleh alat merupakan konvolusi dari sumber, penjalaran, efek lokal, dan yang menjadi pengaruh terbesar adalah respon instrumen. Oleh karena itu, sangat penting untuk menghilangkan respon instrumen pada rekaman seismogram untuk mendapatkan getaran tanah yang sesungguhnya. Penulis menggunakan rekaman gempabumi Lombok pada 31 Maret 2016 pukul 09:34:43 UTC magnitude 4,7 koordinat 8.480 LS dan $116.020 \mathrm{BT}$ dengan kedalaman $10 \mathrm{~km}$ yang terekam oleh seismometer Broadband Trilium120P dan Short-period DS-04A yang terpasang co-located di Stasiun Geofisika Denpasar. Penelitian ini bertujuan untuk meningkatkan nilai korelasi kedua sinyal dari alat yang berbeda sehingga dapat menginterpretasikan getaran tanah sesungguhnya. Untuk memperoleh nilai getaran tanah yang sesungguhnya diperlukan informasi poles dan zeros guna mendapatkan nilai dari fungsi transfer yang selanjutnya didekonvolusi dengan sinyal seismogram. Hasil penghilangan pengaruh respon instrumen menunjukan kemiripan antara sinyal Broadband dan Short-period secara kualitatif dan peningkatan nilai normalisasi korelasi sinyal secara kuantitatif. Perubahan spektrum frekuensi pada sinyal setelah dekonvolusi menunjukan hasil kemiripan antara sinyal setelah koreksi instrumen dibandingkan dengan sebelum koreksi instrumen. Kata kunci: respon instrumen, poles, zeros, Broadband, Short-period.
\end{abstract}

\section{ABSTRACT}

In propagation of seismic signals which recorder by instrument are convolution from source, path, and site effects, the one we know most precisely is the instrument filter. Therefore, it is very important to remove the instrument response to a recorded seismogram to gain true ground motions. The authors use a recording of Lombok earthquake on March 31th, 2016 at 09:34:43 UTC 4.7 magnitude coordinate 8,480 LS and 116,020 $B T$ with a depth of $10 \mathrm{~km}$ which recorded on seismometers Broadband TSA-100S and Shortperiod DS-04A attached co-located in Geophysics Station Denpasar. This study aims to increase the correlation value of the two signals from different sensors so that they can interpret real ground motions.to obtain the value of true ground motions which are required information poles and zeros to get the value of the transfer functions which further deconvoluted to the seismogram signal. The result of the removal of the influence of the instrument response shows the similarity between the Broadband signal and Short-period qualitatively and an increase in the value of normalized correlation signal quantitatively. Changes in the signal frequency spectrum after deconvolution results show similarities between the signals after the correction instrument than the signals before the correction instrument.

Keywords: instrument response, poles, zeros, Broadband, Short-period 


\section{Pendahuluan}

Para ahli seismologi mencoba untuk mendapatkan informasi tentang proses fisik dalam bumi dengan merekam dan menganalisis getaran seismik. Dalam proses penjalarannya, gelombang seismik yang melewati batuan akan mengalami fenomena fisik seperti refleksi, refraksi, transmisi, difraksi, interferensi, dll.

Stasiun Geofisika Denpasar mengoperasikan secara co-located sensor seismometer Broadband Trilium-120P dan Short-period DS04A. Seismometer Broadband dan accelerometer telah beroperasi sejak tahun 2005, sedangkan seismometer Short-period telah diinstalasi bulan Desember 2015.

Saat terjadi gempabumi, sinyal yang terekam oleh seismometer Broadband dan Short-period tersebut, menghasilkan output sinyal yang berbeda. Data mentah sinyal yang diperoleh dari seismometer bukan merupakan getaran tanah yang sesungguhnya melainkan hasil konvolusi dari proses sumber, penjalaran, dan respon instrumen [1, 2, 3]. Jika hal ini diterapkan pada sensor co-located, maka efek dari sumber dan penjalaran adalah sama, sehingga satu-satunya hal yang mempengaruhi perbedaan output dari dua seismometer tersebut adalah respon instrumen.

Penelitian sebelumnya [4] melakukan koreksi respon instrumen pada seismometer Short-period (Mark Products L4) dan Broadband (Guralp CMG6TD) co-located pada jaringan AVO (Alaska Volcano Observatory). Perhitungan fungsi transfer masing-masing seismometer tersebut dilakukan dalam domain frekuensi. Hasil penelitian menunjukkan bahwa sinyal seismik yang semula berbeda pada masing-masing seismometer, setelah dilakukan koreksi respon instrumen menghasilkan bentuk sinyal yang hampir sama.

Penelitian yang serupa [5] dengan menggunakan seismometer Short-period (Mark Product L4C3D) dan Broadband (STS-2) terhadap data gempabumi Jepang 5 September 2004. Hasil penelitian menunjukkan bahwa data sinyal gempabumi setelah dikoreksi dengan respon instrumen mengalami perubahan dari data sebelum dikoreksi untuk masing-masing seismometer. Setelah dibandingakan data untuk seismometer Short-period dan Broadband yang telah dikoreksi, menunjukkan sinyal yang hampir sama.

Pengukuran akurat dari pergerakan medium batuan ketika dilewati oleh gelombang gempabumi dalam satuan fisis, seperti perpindahan $(\mathrm{m})$, kecepatan $(\mathrm{m} / \mathrm{s})$, dan percepatan $(\mathrm{m} / \mathrm{s} 2)$, sangat penting dilakukan untuk analisis lebih lanjut.

Penelitian ini diharapkan meningkatkan nilai korelasi kedua sinyal dari alat yang berbeda sehingga dapat menginterpretasikan getaran tanah sesungguhnya yang direpresentasikan oleh sinyal gelombang gempabumi, sehingga dapat memperjelas bentuk sinyal gempabumi yang ditinjau.

\section{Metodologi}

Sinyal seismik mengalami penyimpangan akibat fungsi transfer dari instrumen seismometer, sehingga dibutuhkan metode untuk menghilangkan pengaruh instrumen, dan memperoleh respon getaran tanah yang sesungguhnya. Poles and zeros digunakan untuk mendapatkan nilai dari fungsi transfer yang selanjutnya didekonvolusi dengan sinyal seismogram.

Sinyal seismik yang terekam pada seismogram berbeda dengan sinyal sesungguhnya akibat fungsi transfer dari instrumen seismometer. Poles and zeros digunakan untuk memperoleh nilai fungsi transfer seismometer yang selanjutnya fungsi transfer tersebut digunakan untuk mengoreksi sinyal mentah seismogram. Poles merupakan akar-akar polinomial dari penyebut $F(s)$ pada fungsi transfer $T(s)$ yang menyebabkan fungsi transfer $T(s)$ bernilai tak terhingga. Zeros merupakan akar-akar polinomial dari pembilang $G(s)$ yang menyebabkan fungsi transfer $T(s)$ bernilai nol.

Prinsip dasar dari sistem linear mengasumsikan sebuah sinyal input dari instrumen $x(t)$ memiliki output sinyal $y(t)$. Ketika input sinyal diperbesar ( $x(t)$ dikalikan dengan suatu konstanta) maka output sinyal $\mathrm{y}(\mathrm{t})$ akan mengalami perbesaran sama dengan konstanta pengali. Fungsi respon frekuensi dinyatakan sebagai rasio dari transformasi Fourier dari $\mathrm{y}(\mathrm{t})$ dan $\mathrm{x}(\mathrm{t})$ yang dinyatakan sebagai [3]:

$$
\begin{aligned}
& T(j \omega)=\frac{Y(j \omega)}{X(\omega)} \\
& T(j \omega)=\frac{1}{(1+j \omega R C)}
\end{aligned}
$$

$$
\begin{array}{ll}
T(j \omega) & =\text { fungsi respon frekuensi } \\
X(j \omega) & =\text { input sinyal dari transformasi Fourier } \\
Y(j \omega) & =\text { output sinyal transformasi Fourier } \\
1 & =\text { bilangan imajiner } \\
\omega & =\text { frekuensi sudut (rad/detik) }
\end{array}
$$


Persamaan (2) dapat dinyatakan dalam bentuk polinomial sebagai [4]:

$$
T(j \omega)=\frac{\left(a_{11}+a_{1}(j \omega)+a_{2}(j \omega)^{2}+\cdots\right)}{\left(b_{1}+b_{1}(j \omega)+b_{2}(j)^{2}+\cdots\right)}
$$

Dalam bentuk poles and zeros persamaan (3) dapat dinyatakan dalam bentuk [3]:

$$
T_{\mathrm{d}}(j \omega)=c \frac{\left.\left(j e-z_{1}\right) j e-z_{2}\right)}{\left.\left(j e-p_{1}\right) d \sigma-p_{2}\right]}
$$

Dengan,

$$
\text { c } \quad=\text { konstanta normalisasi }
$$

Amplitudo dan fase dari masing-masing frekuensi dihitung dengan persamaan nilai fungsi kompleks dari $\mathbf{T}_{\mathbb{a}}$ :

$$
\begin{gathered}
A(\omega)=\sqrt{\operatorname{Re}\left(T_{d}(\omega)\right)^{2}+\operatorname{Im}\left(T_{d}(\omega)\right)^{2}} \\
\phi(\omega)=\tan ^{-1} \frac{\operatorname{lm}(\mathrm{Td}(\omega))}{\operatorname{Re}(\mathrm{Td}(\omega))}
\end{gathered}
$$

Respon kecepatan $\mathbb{T}_{v}(\omega)$ dihitung dengan persamaan:

$$
\mathrm{T}_{v}(\omega)=\frac{\mathrm{T}_{\mathrm{d}}(\mathrm{\theta})}{\theta}
$$

Output dari suatu seismograf dalam domain frekuensi merupakan gabungan dari getaran tanah pada lokasi sensor $\mathrm{U}(\omega)$ dan kombinasi efek dari seismograf $A_{d}(\omega)$ (poles, zeros, dan sensitivitas) yang dinyatakan dalam persamaan:

$$
Z(\omega)=U(\omega) \cdot A_{d}(\omega)(8)
$$

Dalam tulisan ini menggunakan sinyal gempabumi lokal (kurang dari 10 derajat) yang tercatat di kedua seismometer Broadband Trilium-120P dan Short-period DS-04A di Stasiun Geofisika Denpasar. Gempabumi berhasil tercatat adalah gempabumi magnitudo 4,7 yang mengguncang wilayah Lombok pada 31 Maret 2016 pada pukul 09:34:43 UTC yang berlokasi $13 \mathrm{~km}$ barat laut kota Mataram Nusa Tenggara Barat tepatnya pada koordinat 8.480 LS dan 116.020 BT. Lokasi gempabumi yang sangat dekat dengan ibu kota NTB dan beberapa tempat wisata di Lombok tersebut dirasakan hingga Denpasar. Guncangan gempabumi dirasakan III-IV MMI di Mataram dan Lombok Utara, untuk wilayah Kuta, Denpasar, dan Senggigi dirasakan II-III MMI. Ketika sinyal gempabumi terekam oleh seismometer, akan menghasilkan output yang dipengaruhi oleh respon instrumen seismometer tersebut yang diberikan oleh fungsi transfer. Untuk seismometer pendulum sederhana maupun Broadband yang memenuhi syarat sistem linier time invariant yaitu sistem yang memenuhi prinsip superposisi dan karakteristik input-output nya tidak berubah terhadap waktu, secara umum memiliki fungsi transfer $\mathrm{T}(\mathrm{s})$ sebagai berikut:

$$
\mathrm{G}(\mathrm{s})=\mathrm{T}(\mathrm{s}) \cdot \mathrm{F}(\mathrm{s})
$$

dengan $\mathrm{F}(\mathrm{s})$ dan $\mathrm{G}(\mathrm{s})$ merepresentasikan transformasi Laplace dari input dan output sistem. Fungsi transfer $\mathrm{T}(\mathrm{s})$ dalam poles dan zeros adalah

$$
\mathrm{T}(\mathrm{s})=\mathrm{G} \times \mathrm{Cx} \frac{\Pi_{j=1}^{\mathrm{L}}\left(\mathrm{s}-\mathrm{z}_{\mathrm{j}} \mathrm{s}\right.}{\Pi_{\mathrm{i}=1}^{\mathrm{L}}\left(\mathrm{s}-\mathrm{F}_{\mathrm{k}}\right)}
$$

Dengan $\mathrm{G}$ adalah gain dalam satuan counts $/ \mathrm{m} / \mathrm{s}$, C merupakan konstanta normalisasi, $\mathbf{z}_{1}$ menunjukkan sejumlah $\mathrm{L}$ zeros, dan $\mathrm{p}_{\mathrm{k}}$ menunjukkan sejumlah $\mathbf{N}$ poles [4]. Nilai poles dan zeros dari seismometer Broadband Trilium120P sebagai berikut:

$$
\begin{aligned}
& \text { Zeros: } \\
& 00 \\
& -106-158 \\
& \text { Poles: } \\
& -0.03859+0.03649 \mathrm{i} \\
& -0.03859-0.03649 \mathrm{i} \\
& -190 \\
& -158-193 \mathrm{i} \\
& -158-193 \mathrm{i} \\
& -639+1418 \mathrm{i} \\
& -639-1418 \mathrm{i}
\end{aligned}
$$

Dan nilai poles and zeros dari seismometer ShortperiodDS-04A sebagai berikut:

$$
\begin{aligned}
& \text { Zeros: } \\
& 00 \\
& \text { Poles: } \\
& -4.396+4.485 \mathrm{i} \\
& -4.396-4.485 \mathrm{i} \\
& -251.2 \\
& -320
\end{aligned}
$$

Dalam penentuan kemiripan sinyal digunakan fungsi normalisasi korelasi silang [6]:

$$
\rho(l)=\frac{r_{x y}(0)}{\sqrt{r_{x x} 0 / r_{y y}(0)}}
$$

Dimana $\rho($ (]) merupakan nilai normalisasi korelasi silang dengan rentang 0 sampai $1, r_{x y}(b)$ korelasi silang antara dua sinyal dalam fungsi $x$ dan $y$, $\gamma_{x x}(0)$ dan $r_{y y}(0)$ adalah korelasi diri pada $l=0$ 
yang memiliki nilai sama dengan akumulasi kuadrat sinyal.

Perhitungan menggunakan perangkat lunak Matlab 7.11 (R2010b). Untuk dapat menghitung nilai fungsi transfer masing-masing seismometer, maka diperlukan informasi mengenai parameter masing-masing seismometer seperti poles, zeros, konstanta generator dan gain ADC, sehingga diperoleh fungsi koreksi instrumen. Hasil koreksi instrumen kedua sinyal, dibandingkan secara kualitatif maupun kuantitatif. Secara kualitatif dilakukan perbandingan secara visual dan kuantitatif dengan menggunakan nilai normalisasi korelasi silang sinyal. Selain itu, penulis juga membandingkan frekuensi sinyal setelah koreksi instrumen dengan frekuensi sinyal sebelum koreksi instrumen.

\section{Hasil dan Pembahasan}

Sejak pemasangan seismometer Short-period DS-04A dalam satu ruangan dengan seismometer Broadband Trilium-120P bulan Desember 2015 telah berhasil mencatat gempabumi lokal dangkal yang terjadi pada 31 Maret 2016 pukul 09:34:43 UTC magnitude 4,7 koordinat 8.480 LS dan 116.020 BT dengan kedalaman $10 \mathrm{~km}$. Gempabumi tersebut tercatat baik di kedua seismometer Broadband Trilium-120P dan Shortperiod DS-04A pada komponen vertikal pada 09:34:59,3 UTC.
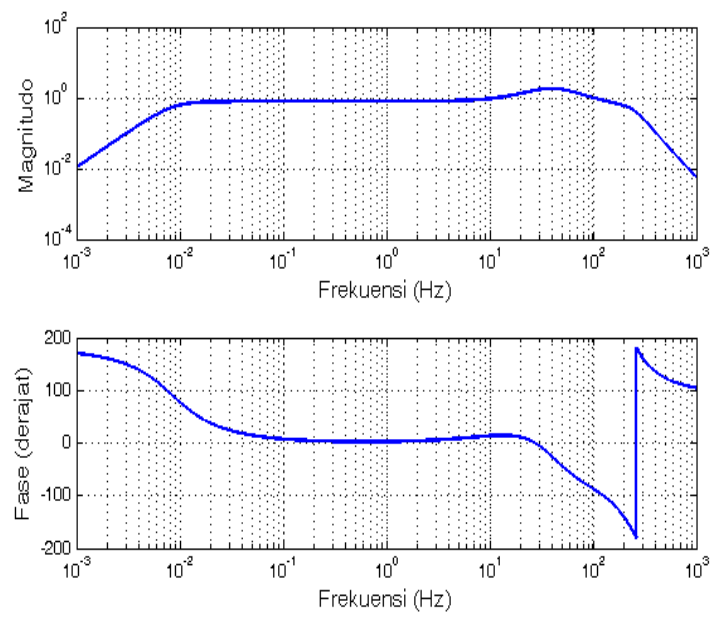

Gambar 1. Fungsi respon frekuensi seismometer Broadband Trilium-120P dalam bentuk magnitudo dan fase.

Selanjutnya sinyal seismik yang telah tercatat di kedua seismometer tersebut telah mengalami penyimpangan akibat fungsi transfer dari instrumen seismometer. Jadi, dibutuhkan metode untuk menghilangkan pengaruh yang tidak diinginkan untuk mendapatkan respon getaran tanah yang sesungguhnya. Maka digunakanlah poles dan zeros untuk mendapatkan nilai dari fungsi transfer yang selanjutnya didekonvolusi dengan sinyal seismogram.

Penelitian koreksi respon instrumen dalam domain frekuensi telah dilakukan oleh Haney dkk. [4], Kusuma dan Suryanto [5], Gunawan [7] sedangkan yang melakukan koreksi respon instrumen dalam domain waktu adalah Anderson dan Lees [8].
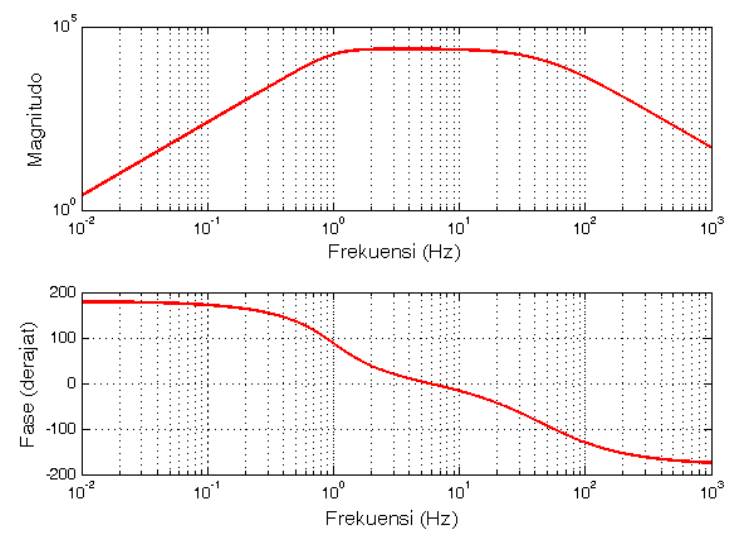

Gambar 2. Fungsi respon frekuensi seismometer Short-period DS-04A dalam bentuk magnitudo dan fase.

Berdasarkan nilai poles dan zeros dari masingmasing komponen seismometer Broadband Trilium-120P dan Short-periodDS-04A penulis membuat grafik fungsi respon frekuensi seismometer (Gambar 1 dan Gambar 2). Grafik ini merupakan acuan untuk koreksi instrumen sehingga dapat mendekonvolusi pengaruh respon instrumen dari catatan seismogram agar memperoleh getaran tanah yang sesungguhnya.

Analisis Sebelum Koreksi Instrumen. Data sinyal dimulai dari waktu origin time gempabumi Lombok 09:34:43 UTC. Gelombang P tiba di Stasiun Geofisika Denpasar pada pukul 09:34:59,3 UTC, 16 detik waktu dalam proses penjalarannya.

Pada Gambar 3 menunjukan perbandingan tampilan antara sinyal rekaman asli dari Broadband Trilium-120P (biru) dengan sinyal Short-period DS-04A (merah). Perbandingan kedua sinyal secara kualitatif visual menunjukan adanya perbedaan yang ditunjukan pada Gambar 4 dengan selisih antara kedua sinyal cukup besar. Berdasarkan Gambar 2 nilai maksimum dari selisih antara sinyal Broadband dan Short-period mencapai $1.0314 \mathrm{e}+5$ count. 


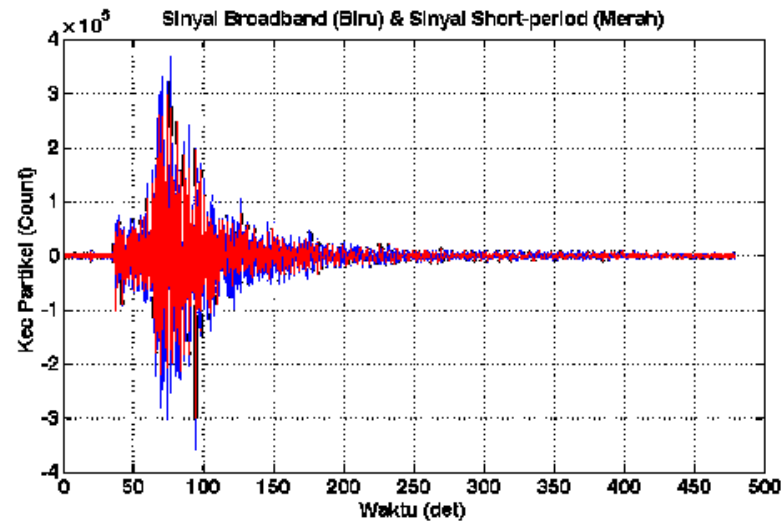

Gambar 3. Perbandingan tampilan sinyal sebelum koreksi instrumen pada seismogram Broadband Trilium-120P (biru) dan Short-period DS-04A (merah)

Rekaman sinyal Broadband Trilium-120P mempunyai sampling $40 \mathrm{~Hz}$ sedangkan rekaman Short-period DS-04A mempunyai sampling yang lebih besar yaitu $100 \mathrm{~Hz}$. Untuk mengkorelasikan kedua sinyal ini dilakukan resampling pada sinyal Short-period menjadi $40 \mathrm{~Hz}$. Perbedaan respon instrumen pada kedua alat mengakibatkan sinyal yang diterima berbeda walaupun sumber, medium yang dilewati selama penjalaran dan efek tapak lokal menunjukan kesamaan. Untuk menunjukan nilai korelasi secara kuantitatif digunakan normalisasi korelasi sinyal. Dari hasil normalisasi korelasi sinyal pada sinyal sebelum dilakukan koreksi diperoleh hasil yang nilai normalisasi korelasi 0,9011 . Dua buah sinyal dikatakan sama apabila memiliki nilai normalisasi korelasi sebesar 1. Jadi, masih terdapat perbedaan sebesar 0,0989 akibat adanya pengaruh respon instrumen.
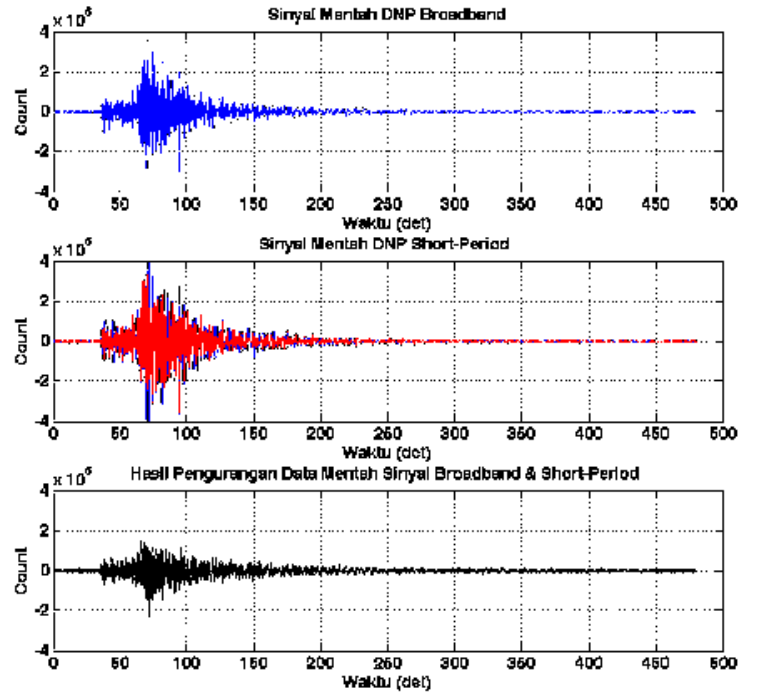

Gambar 4. Hasil pengurangan antara sinyal mentah seismogram Broadband Trilium-120P (biru) dan Shortperiod DS-04A (merah)
Sinyal seismik yang dipancarkan oleh sumber dan mengalami penyimpangan dilemahkan akibat penyebaran geometris dan faktor redaman dan karena refleksi, difraksi, konversi dan gangguan lainnya selama propagasi melalui media bumi [9]. Sinyal seismik memiliki penyimpangan yang dihasilkan dari fungsi transfer dari seismometer. Oleh karena itu, diperlukan dekonvolusi pengaruh instrumen untuk mendapatkan getaran tanah yang sesungguhnya. Faktor penting yang menjadi kunci dalam koreksi respon instrumen adalah mengetahui parameter poles dan zeros seismometer [5].

Analisis Setelah Koreksi Instrumen. Sinyal mentah hasil rekaman seismometer (Gambar 3) didekonvolusi dengan fungsi respon frekuensi untuk tiap masing-masing sensor (Gambar 1 dan Gambar 2). Dekonvolusi ini bertujuan untuk menghilangkan pengaruh respon instrumen pada rekaman sinyal seismik sehingga diharapkan getaran tanah yang sesungguhnya yang tiba di Stasiun Geofisika Denpasar akibat gempa bumi Lombok 31 Maret 2016 dapat terlihat.

Perbedaan jenis seismograf pencatat gempabumi menimbulkan perbedaan hasil rekaman dalam sumber yang sama. Seismometer Broadband dapat mencakup keseluruhan sinyal hingga frekuensi rendah. Namun, seismometer Shortperiod lebih baik dalam pengukuran gelombang frekuensi tinggi.

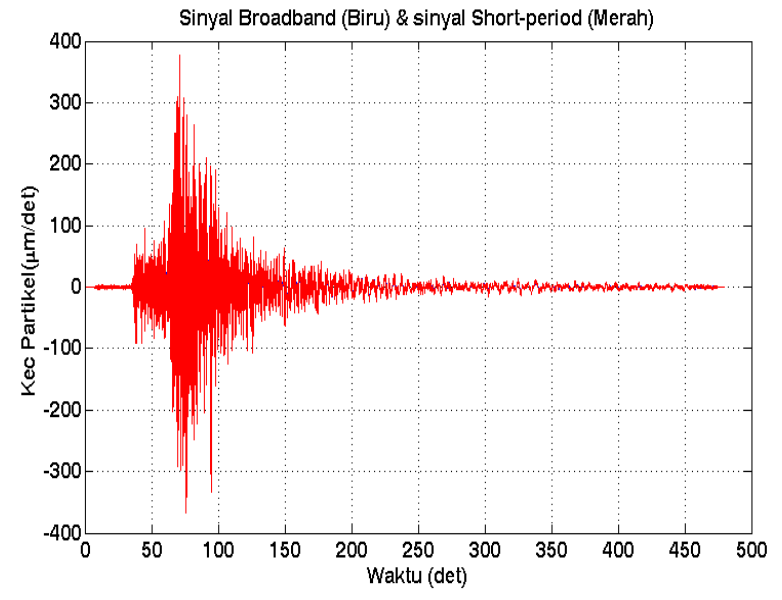

Gambar 5. Perbandingan tampilan sinyal setelah koreksi instrumen pada seismogram Broadband Trilium-120P (biru) dan Short-period DS-04A (merah)

Secara visual Gambar 5 menunjukan kemiripan sinyal satu sama lain. Dari hasil perhitungan normalisasi korelasi sinyal setelah dilakukan koreksi instrumen berupa penghilangan respon instrumen pada sinyal dengan dekonvolusi sesuai dengan fungsi respon frekuensi diperoleh hasil berupa peningkatan nilai korelasi sebesar 0.9985 . 
Nilai korelasi mendekati satu (selisih 0.0015) menunjukan bahwa hasil dari koreksi instrumen menunjukan kemiripan yang sangat tinggi. Berdasarkan Gambar 5 nilai maksimum dari selisih antara sinyal Broadband dan Short-period setelah koreksi instrumen mencapai 25,112 mikrometer per detik.

Perbandingan Spektrum Frekuensi. Untuk mengubah sinyal dari domain waktu ke domain frekuensi menggunakan Fast Fourier Transform (FFT). Dari hasil FFT sinyal Broadband dan Shortperiod diperoleh hasil berupa spektrum frekuensi.

Penulis membandingkan hasil spektrum frekuensi sebelum dan sesudah koreksi instrumen (Gambar 6). Berdasarkan hasil tersebut secara visual dapat dilihat bahwa terjadi perubahan sinyal yang cukup signifikan pada seismometer Short-period. Pada sinyal Broadband sebelum koreksi instrumen terjadi pergeseran ke frekuensi rendah sedangkan pada sinyal Short-period menunjukan penurunan sinyal frekuensi tinggi dan munculnya sinyal frekuensi rendah dari $0,01-0,20 \mathrm{~Hz}$.
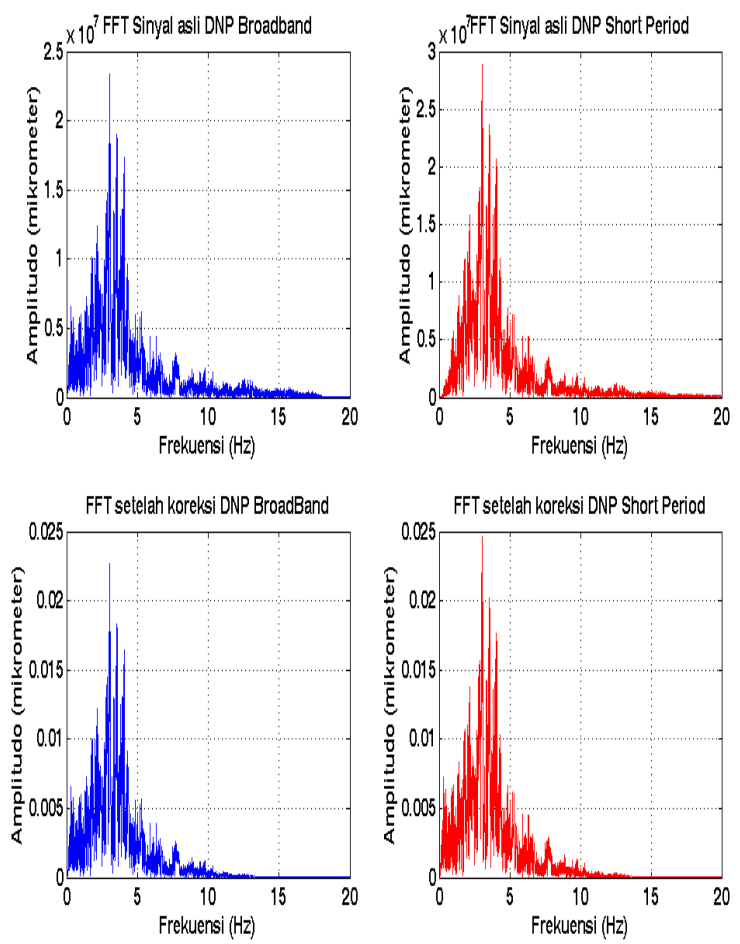

Gambar 6. Perbandingan spektrum frekuensi seismogram sebelum (hitam) dan sesudah (merah) dari Broadband Trilium-120P dan Short-period DS-04A.
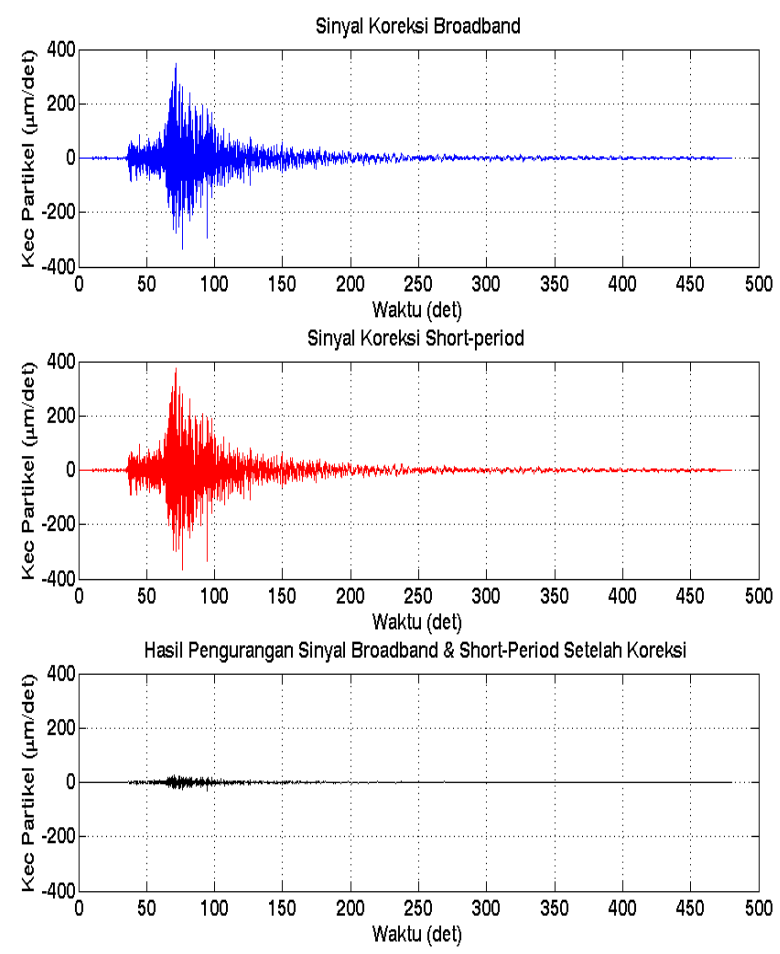

Gambar 7. Hasil pengurangan antara sinyal setelah koreksi seismogram Broadband Trilium-120P (biru) dan Short-period DS-04A (merah)

Sensor Short-period memiliki rentang frekuensi tinggi $(0.5-100 \mathrm{hz})$ sangat baik dalam mencatat sinyal gempa bumi lokal, sedangkan sensor BB memiliki rentang frekuensi yang lebih lebar $(0.0028$ - $100 \mathrm{hz})$ sehingga dapat mencatat gempabumi lokal maupun teleseismik. Hasil korelasi tinggi dari 2 sinyal seismogram ini membuktikan bahwa kedua instrumen mencatat rekaman sinyal dengan baik. Lokasi Stasiun Geofisika Denpasar berada di tengah kota Denpasar yang menyebabkan sulit untuk mendeteksi sinyal gempabumi mikro dengan amplitudo rendah karena Dengan adanya sensor co-located membuat fase gelombang $\mathrm{P}$ sulit terlihat karena bercampur noise. Untuk itu, diperlukan sensor short period yang mencatat gempabumi mikro lebih baik. Hasil pick time gelombang $\mathrm{P}$ pada Short-period dapat dijadikan acuan untuk pick time pada seiscomp sensor DNP.

\section{Kesimpulan}

Berdasarkan korelasi sinyal rekaman gempabumi Lombok 31 Maret 2016 pada dua seismometer co-located Broadband Trilium-120P dan Shortperiod DS-04A yang terpasang di Stasiun Geofisika Denpasar diperoleh perbedaan hasil sebelum dan setelah dilakukan koreksi instrumen. Dari hasil normalisasi korelasi sinyal pada sinyal 
sebelum dilakukan koreksi diperoleh hasil yang nilai normalisasi korelasi 0,9011 . Kemudian setelah dilakukan koreksi instrumen terjadi peningkatan nilai korelasi sebesar 0.9985 . Jadi, masih terdapat perbedaan sebesar 0,0989 akibat adanya pengaruh respon instrumen. Hasil setelah koreksi instrumen dari kedua sinyal menunjukan adanya kemiripan bentuk dan frekuensi sinyal setelah dikoreksi baik secara kualitatif maupun kuantitatif. Pada spektrum frekuensi sinyal Broadband sebelum koreksi instrumen terjadi pergeseran ke frekuensi rendah sedangkan pada sinyal Short-period menunjukan penurunan sinyal frekuensi tinggi dan munculnya sinyal frekuensi rendah dari $0,01-0,20 \mathrm{~Hz}$.

\section{Daftar Pustaka}

[1] Havskov, J. dan Ottemöller, L., Routine Data Processing in Earthquake Seismology, Springer, New York, 2010.

[2] Stein, S. dan Wysession, M., An Introduction to Seismology, Earthquake, andEarth Structure, Blackwell Publishing Ltd, USA, 2003.

[3] Scherbaum, F., Of Poles and Zeros, Kluwer Academic Publisher, Netherlands, 2001.

[4] Haney, M. M., Power, J., West, M. dan Michaels, P., Causal Instrument Corrections for Short-period and Broadbannd Seismometers, Seismological Research Letters, no. doi:10.1785/0220120031, Vol. 83, p. 834-845, 2012.

[5] Kusuma, E., dan Suryanto, W., Instrument Corrections for Broadband and Short-period Seismometers (Case Study: Japan's Earthquake September 5th 2004), The Third Basic Science International Conference, p. P14-1 - P14-3, 2013.

[6] Proakis, J. G. dan Manolakis, D. G., Digital Signal Processing, Principles, Algorithms, and Application, Third Edition.Prentice-hall International, INC, New Jersey. Climate, 26, 110-132, doi:10.1175/JCLI-D-12-00100.1., 1996.

[7] Gunawan, H., Analisis Data Geofisika Monitoring Gunungapi Berdasarkan Analitik dan Diskrit (Bagian II): Contoh Kasus Koreksi Instrumen dalam Penentuan Amplitudo Seismogram Digital, Bulletin Vulkanologi dan Bencana Geologi, Vol. 3 p. 13-16, 2008.

[8] Anderson, J. F. dan Lees, J. M., Instrument Corrections by Time-Domain Deconvolution, Seismological Research Letters, no. doi:10.1785/0220130062, Vol. 85, p. 197-201, 2014.

[9] Borman, P., New Manual of Seismological Observatory Practice-NMSOP, GFZ, Postdam (versi elektronik), 2009. 